\title{
BLADDER EXSTROPHIES AND EPISPADIAS COMPLEX: PREVALENCE, ASSOCIATED ANOMALIES, PRENATAL DIAGNOSIS AND SURVIVAL IN THE NORTH OF ENGLAND
}

\author{
D. Jayachandran ${ }^{1}$, M. Bythell ${ }^{2}$, M. Ward Platt ${ }^{2}$, J. Rankin $^{3}$ \\ ${ }^{1}$ Darlington Memorial Hospital, Darlington, ${ }^{2}$ Regional Maternity Survey Office, ${ }^{3}$ Institute of Health and \\ Society, Newcastle University, Newcastle Upon Tyne, UK
}

Background and aims: The bladder exstrophy-epispadias complex (BEEC) is the most serious form of abdominal midline malformation but its prevalence in the UK is unknown. We determined the prevalence, associated anomalies, rate of prenatal diagnosis and one year survival of cases in a geographically defined population.

Methods: Cases were identified from 1985 to 2008 from the Northern Congenital Abnormality Survey (NorCAS), covering a population of approximately 3 million in the north of England.

Results: From a population of 824368 registered births, 42 singleton cases and one twin were identified giving a total prevalence of 5.22 per 100000 (95\%CI 3.77, 7.03). Twenty-nine (69\%) cases were isolated and $13(31 \%)$ cases were associated with other congenital anomalies; $11(26 \%)$ with other structural anomalies and two (4.7\%) with chromosomal anomalies. The male to female ratio was 2.2:1 for all singleton cases and 1.4:1 for isolated cases. The overall live birth prevalence was 4.63 per 100000 live births $(95 \% \mathrm{CI}$ $3.28,6.36)$. For isolated cases, the total prevalence was 3.52 per 100000 births $(95 \% \mathrm{CI} 2.36,5.05)$ and the live birth prevalence was 3.29 per 100000 live births (95\%CI 2.17, 4.79). Four cases (10\%) were detected antenatally by routine ultrasound scan; three had bladder exstrophy and one had cloacal exstrophy. The overall survival of all infants at one year was $95 \%$.

Conclusions: The population prevalence is similar to other countries. There is a low rate of prenatal diagnosis rate and high survival; isolated cloacal exstrophy is particularly rare. 